\title{
G-Banded Karyotypes of Four Egyptian Species of Order Carnivora (Mammalia: Carnivora)
}

\author{
Hemely A. Hassan \\ Cytogenetic Laboratory, Zoology Department, Faculty of Science (Qena), South Valley University, Egypt
}

Accepted July 7, 1999

\begin{abstract}
Summary The chromosomes of 4 carnivorous species were prepared and karyotyped from a bone marrow. 3 species from family Canidae including the Red Fox (Vulpes vulpes), the domestic dog (Canis familiaris) and a wild dog (Lycaon pictus) have a diploid chromosome numbers and fundamental numbers of, $2 \mathrm{n}=38$ and $\mathrm{FN}=72,2 \mathrm{n}=78$ and $\mathrm{FN}=80,2 \mathrm{n}=38$ and $\mathrm{FN}=68$, respectively while the diploid number and fundamental number of Domestic cat (Felis catus) which belongs to the family Felidae are $2 \mathrm{n}=38$ and $\mathrm{FN}=72$. Although the 3 species of $V$. vulpes, L. pictus and F. catus have the $2 n=38$, they are clearly different in their chromosome morphology and G-banded karyotypes.
\end{abstract}

Recently, vertebrate systematics was based almost entirely on comparative morphological studies, recent advances in biochemistry and other areas have enabled systematists to utilize different kinds of data in determining phylogenetic and taxonomic relationships. Although the systematic value of comparing chromosomes of different species was known for several years, vertebrate cytosystematics was largely ignored until the technological breakthrough of Moorhead et al. (1960), Bickham and Baker (1976). However, many studies have indicated that G-banding patterns are conservative in related species of mammals (Pathak et al. 1973) and even between related genera (Evans et al. 1973, Hassan et al. 1994). The studies concerning the chromosome banding pattern of carnivores are not enough (Wurster-Hill and Centerwall 1982). On the other hand G- and R-banding has been investigated several times in the domestic cat but there is a total lack of sequential and counterstain-enhanced fluorescence studies in this species (Kalat et al. 1990).

Order carnivora was exposed for many cytogenetic studies to determine the karyological and phylogenetic relationships among its individuals such as Dutrillaux and Couturier (1983), Wayne et al. (1987), Laikre et al. (1992), Qumsiyeh (1994), Suzuki (1994) and Arnason (1996). The karyotypes of the family Canidae vary considerably in their chromosome number and morphology. The diversity of autosome morphology ranges from completely acrocentric in several species including domestic dog (Canis familiaris, $2 \mathrm{n}=78$ ) and the grey wolf (Canis lupus, $2 \mathrm{n}=78$ ), to entirely metacentric in red fox (Vulpes vulpes, $2 \mathrm{n}=38$ ) and wild dogs (Chiarelli 1965. Wurster-Hill and Centerwall 1982, Makinen 1985, Wayne et al. 1987). The uniformity of the karyotype pattern of family Felidae is recorded by Wurster and Benirschke (1968) and Wurster-Hill and Centerwall (1982) while, 30 species have studied, 25 of them are reported to have a diploid chromosome number of 38 and 5 to have 36 , and the FN varies only from 70 to 76 .

\section{Materials and methods}

Individuals of the 4 species, Vulpes vulpes, Canis familiaris, Lycaon pictus and Catus felis (two mals and two females from each species) were obtained from an animal dealer. They were collected from different localities around Qena city in Upper Egypt.

Air-dried bone marrow slides were prepared for the study of mitotic chromosomes according to Adegoke and Nadesan (1986) with some modifications made by Adegoke and Ejere (1991) and 


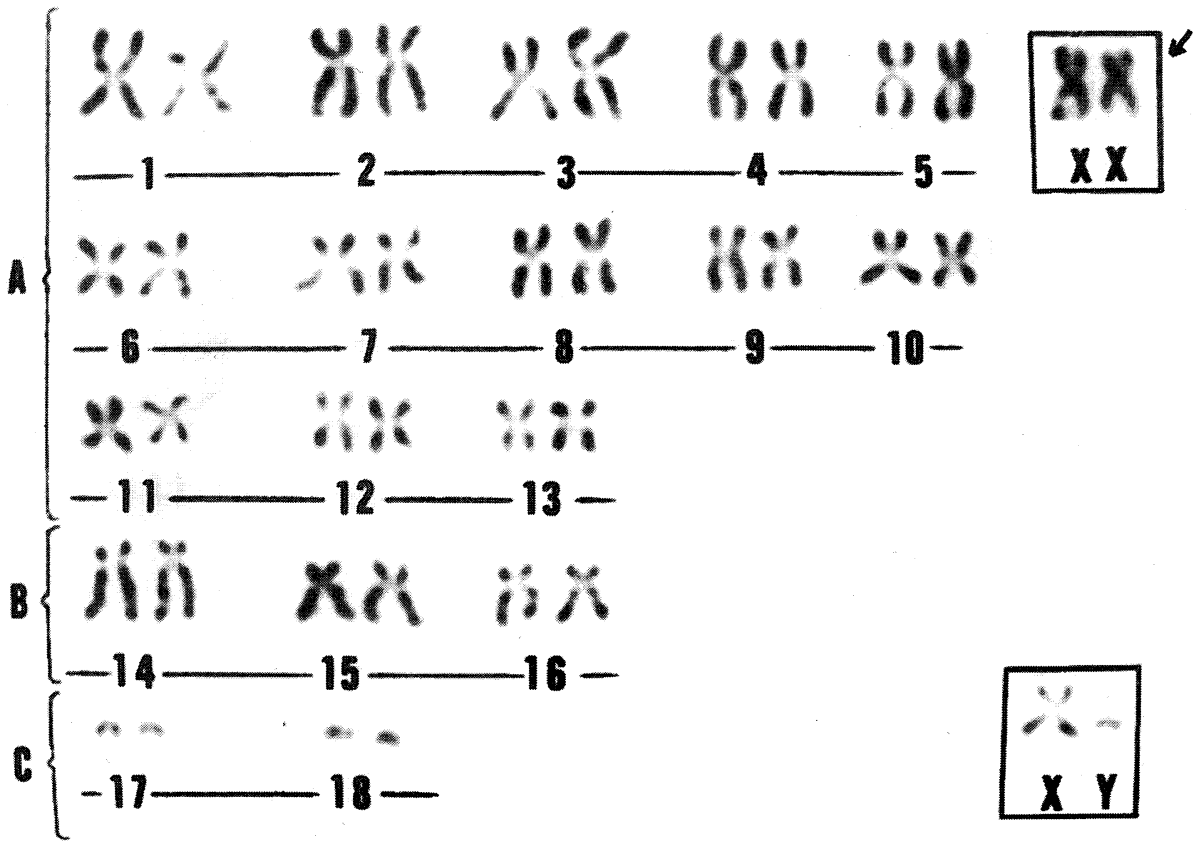

(a)

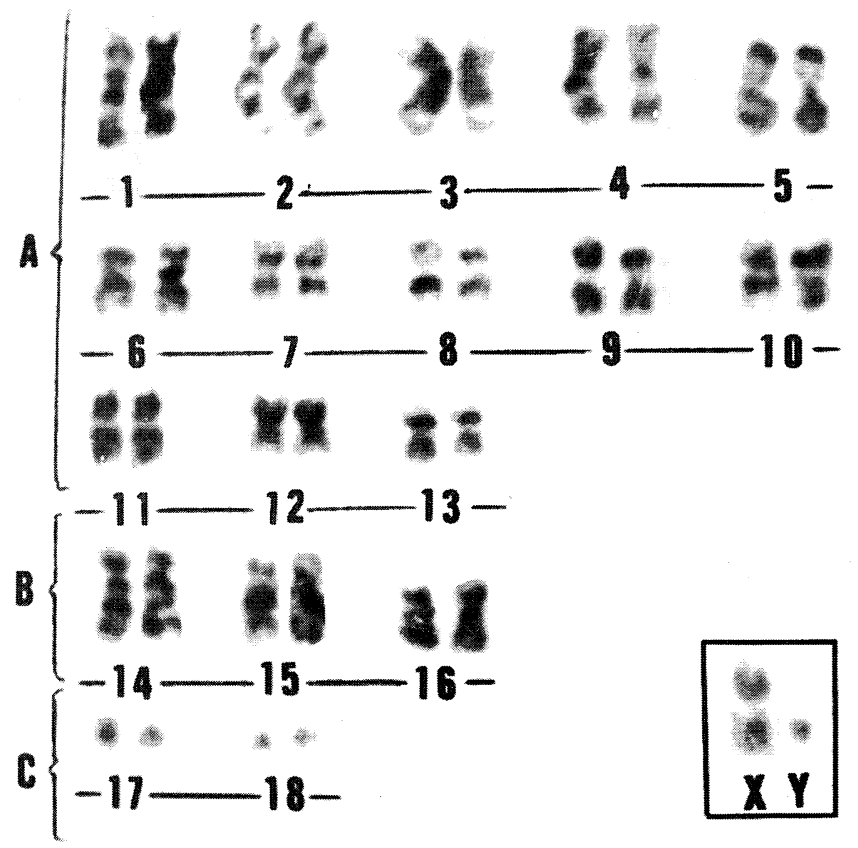

(b)

Fig. 1. Male mitotic karyotypes of Vulpes vulpes, a) conventional Giemsa stain, b) G-banding, arrow indicates to sex chromosomes from a female. 


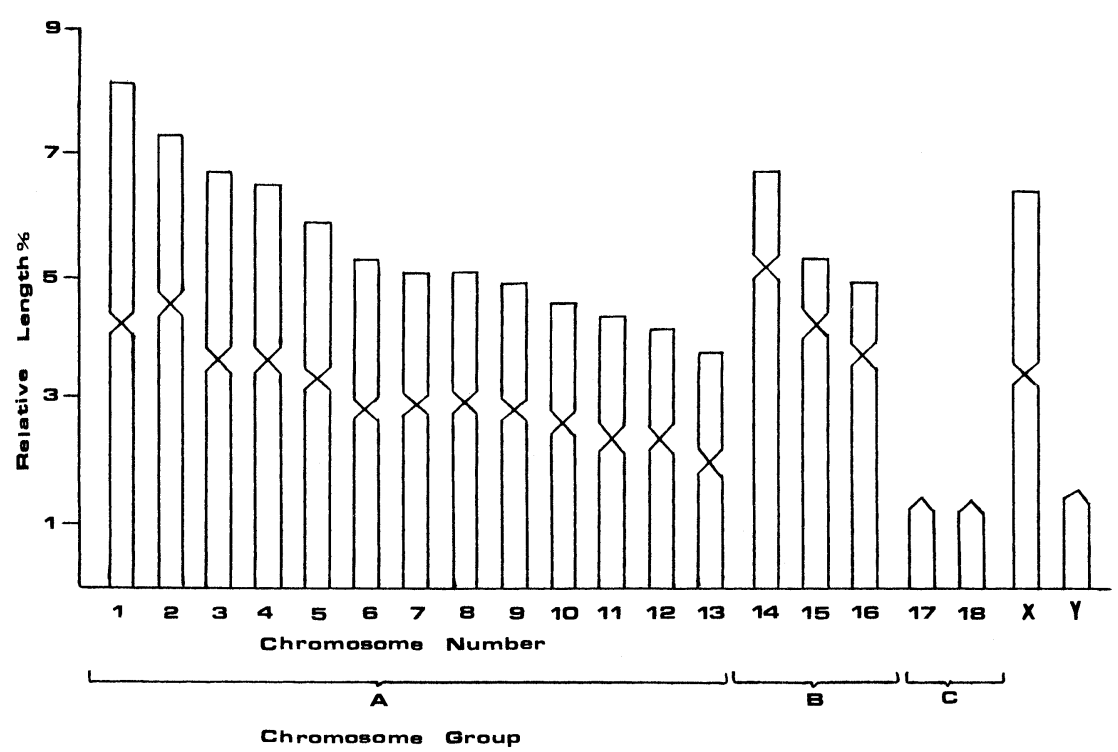

Fig. 2. Idiogram of the chromosomes of male Vulpes vulpes which was constructed in respect to the relative length.

Salama et al. (1995) as follows: Animals were injected with $0.05 \%$ colchicine for $2-3 \mathrm{~h}$ before sacrifice, bone marrow was extracted with $0.56 \% \mathrm{KCl}$, cells from bone marrow were fixed three times with freshly prepared fixative of glacial acetic acid and methanol $(1: 3)$, respectively. Some slides were stained with conventional Giemsa while others were aged for G-banding. The G-banding technique of Seabright (1971) was used. This method involves aging fixed slides, flooding them with $0.025 \%$ buffered trypsin and finally stained with buffered $5 \%$ Geimsa stain, banding of long chromosomes are quite useful for identification of the daughter chromosomes. More than 15 spreads were counted to determine the diploid chromosome number and at least 10 mitotic metaphases were karyotyped from each species. Measurements and calculations were made and chromosome lengths were standardized as a percent of the total complement length. Centromeric position is described according to criteria established by Levan et al. (1964).

\section{Results}

\section{Red fox (Vulpes vulpes)}

$V$. vulpes has $2 \mathrm{n}=38$ and $\mathrm{FN}=72$ arranging in 3 different groups of chromosomes. Group A consists of 13 pairs metacentric chromosomes with relative length ranges from $3.75 \%$ to $8.10 \%$, group B has 3 subtelocentric pairs in which the relative length varying from $4.93 \%$ to $6.67 \%$, group $\mathrm{C}$ has only 2 pairs of microchromosomes which appear to be acrocentrics in some spreads with relative length of $1.38 \%$ and $1.48 \%$. X-chromosome is large metacentric which nearly has the size of no. 14, while Y-chromosome is very small nearly having the same size of no. 17 that appears in some spreads with high resolution to be biarmed (Figs. 1, 2, Table 1).

\section{Domestic dog (Cains familiaris)}

The domestic dog metaphase karyotype consists of 78 chromosomes and FN=80. All autosomes exhibit acrocentric configurations gradually diminishin in size. These features make identification of homologous pairs by conventional staining be very difficult, so the using of Giemsa banding method facilitates this problem. The relative length of the autosomes ranges from $1.17 \%$ to 


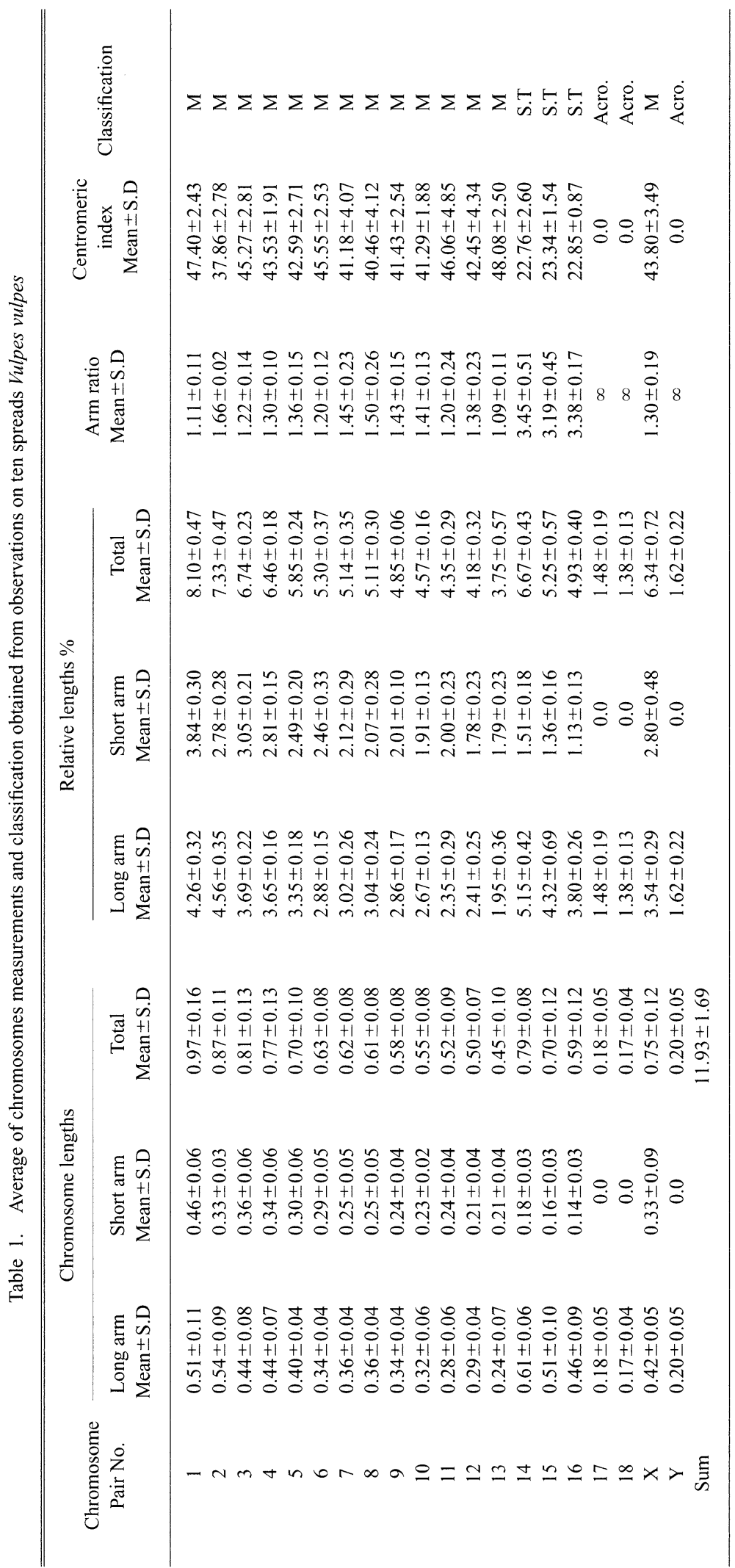




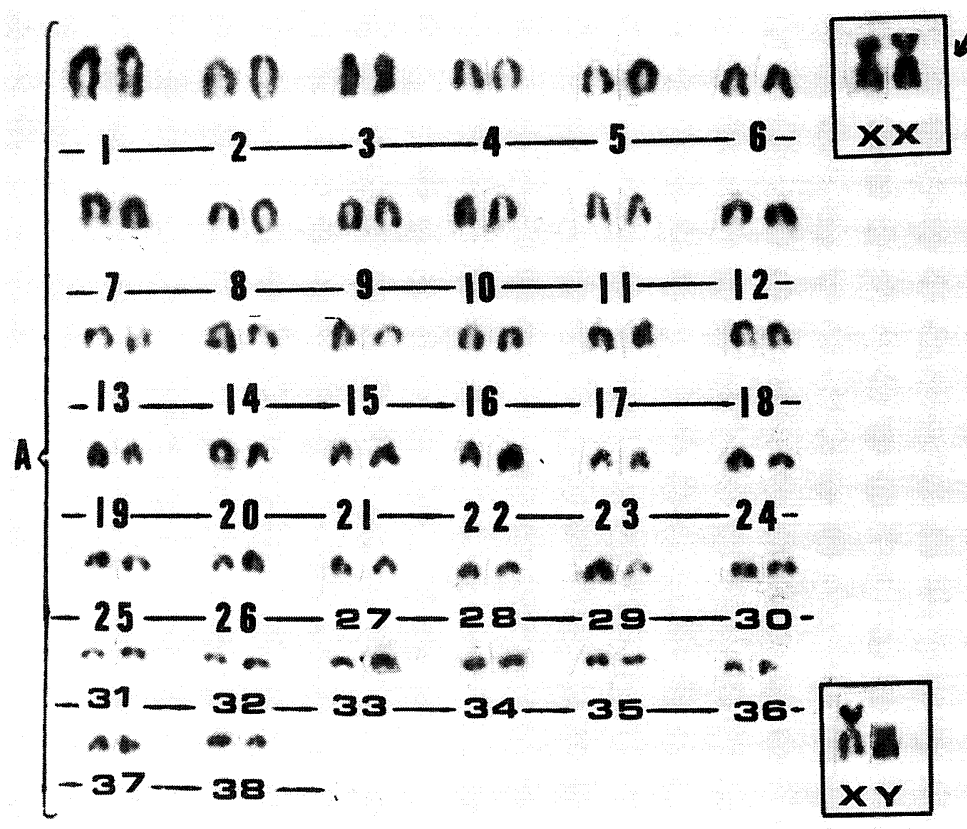

(a)

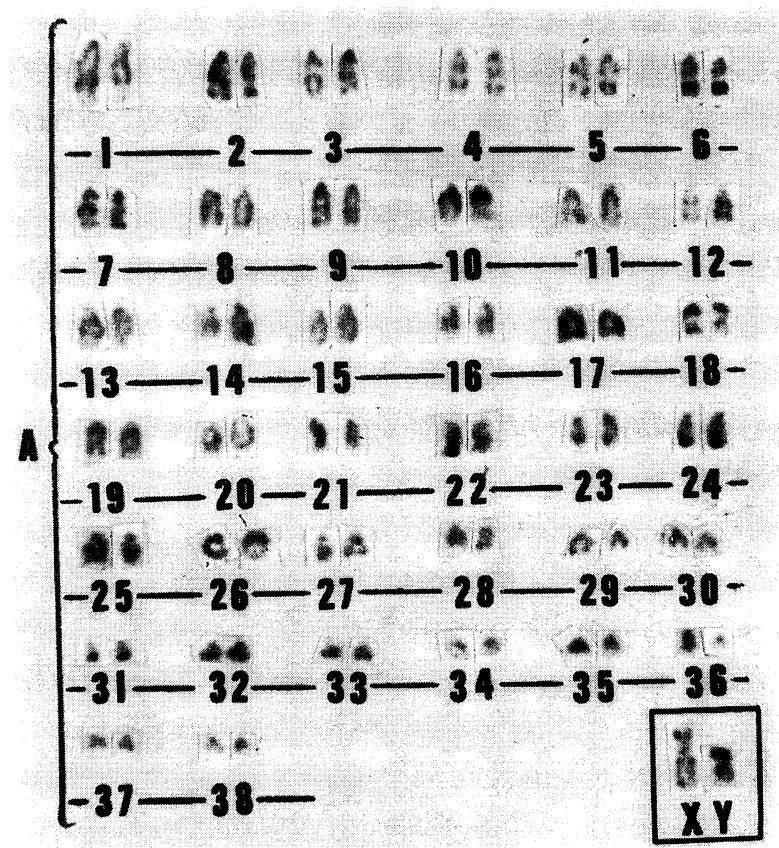

(b)

Fig. 3. Male mitotic karyotypes of Canis familiaris, a) conventional Giemsa stain, b) G-banding, arrow indicates to sex chromosomes from a female. 


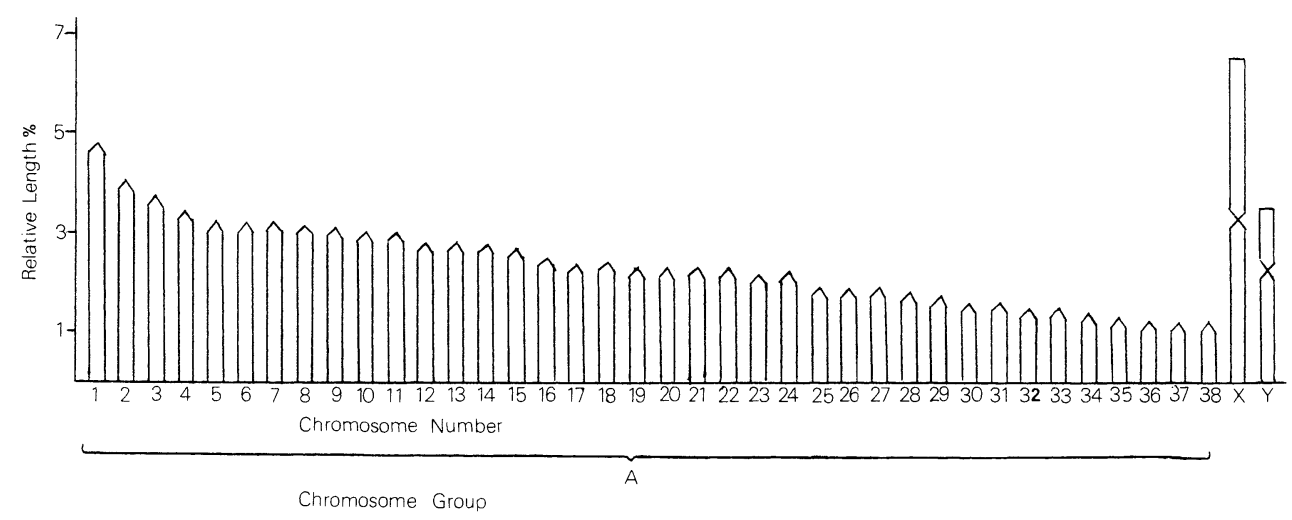

Fig. 4. Idiogram of the chromosomes of male Canis familiaris which was constructed in respect to the relative length.

4.78\%. The metacentric X-chromosome represents the largest one of the karyotype with relative length of $5.46 \%$ while Y-chromosome is medium-sized submetacentric with relative length of 3.5\% (Figs. 3, 4, Table 2).

\section{Wild dog (Lycaon pictus)}

This species has $2 n=38$ and $F N=68$, the chromosomes are arranged in the karyotype in 4 groups as follows: Group A is composed of 6 metacentric pairs with relative length varies from $3.63 \%$ to $6.57 \%$, group B has 3 pairs of submetacentric chromosomes with relative length ranges from $4.46 \%$ to $8.35 \%$, group $\mathrm{C}$ has 5 subtelocentric pairs with relative length ranges from $4.9 \%$ to $7.54 \%$, group D is composed of 4 acrocentric pairs in which the relative length ranges from $2.44 \%$ to $3.97 \%$. Regarding sex chromosomes, X-chromosome is metacentric with relative length of $7.4 \%$ which nearly equals no. 10 in size, while Y-chromosome is microchromosome which appears to be acrocentric with relative length of $1.25 \%$ (Figs. 5, 6, Table 3).

\section{Domestic cat (Felis catus)}

The diploid chromosome number and fundamental number of this species are $2 n=38$ and $\mathrm{FN}=72$ with 4 groups of chromosomes. Giroup A is composed of 4 submetacentric pairs with relative length ranges from $5.28 \%$ to $8.55 \%$ while group B has 6 metacentric pairs with relative length varies from $2.92 \%$ to $7.82 \%$, group C consists of 6 pairs of subtelocentrics in which the relative length ranges from $3.5 \%$ to $6.90 \%$ and the last group D has only 2 acrocentric pairs with relative length of $2.89 \%$ and $2.2 \%$ for the large and smaller ones. X-chromosome is metacentric nearly equals no. 17 in size, while $\mathrm{Y}$ is also metacentric equals no. 16 in size (Figs. 7, 8, Table 4).

\section{Discussion}

The number of species in family Canidae is 35 (Van Gelder 1978). Fundamental and diploid numbers have been published for only about half (19) of the species in which the diploid numbers vary from 34 to 78 and the FN for over $90 \%$ of the reported species range from 66 to 80 (Ward et al. 1987). Several karyological studies were carried out on the red fox. Wodsedalek (1931) described the diploid chromosome number of 42 for this species while Andres (1938) and Mayr et al. (1986) reported the diploid number of 34 and Bishop (1942) a diploid number of 32. The exact diploid number of this species was reported by Renzoni and Omodeo (1972) and Wayne et al. (1987) to be $2 n=38$.

Our karyotypic data of $V$. vulpes (Figs. 1,2) of $2 \mathrm{n}=38$ and $\mathrm{FN}=72$ are in complete agreement 


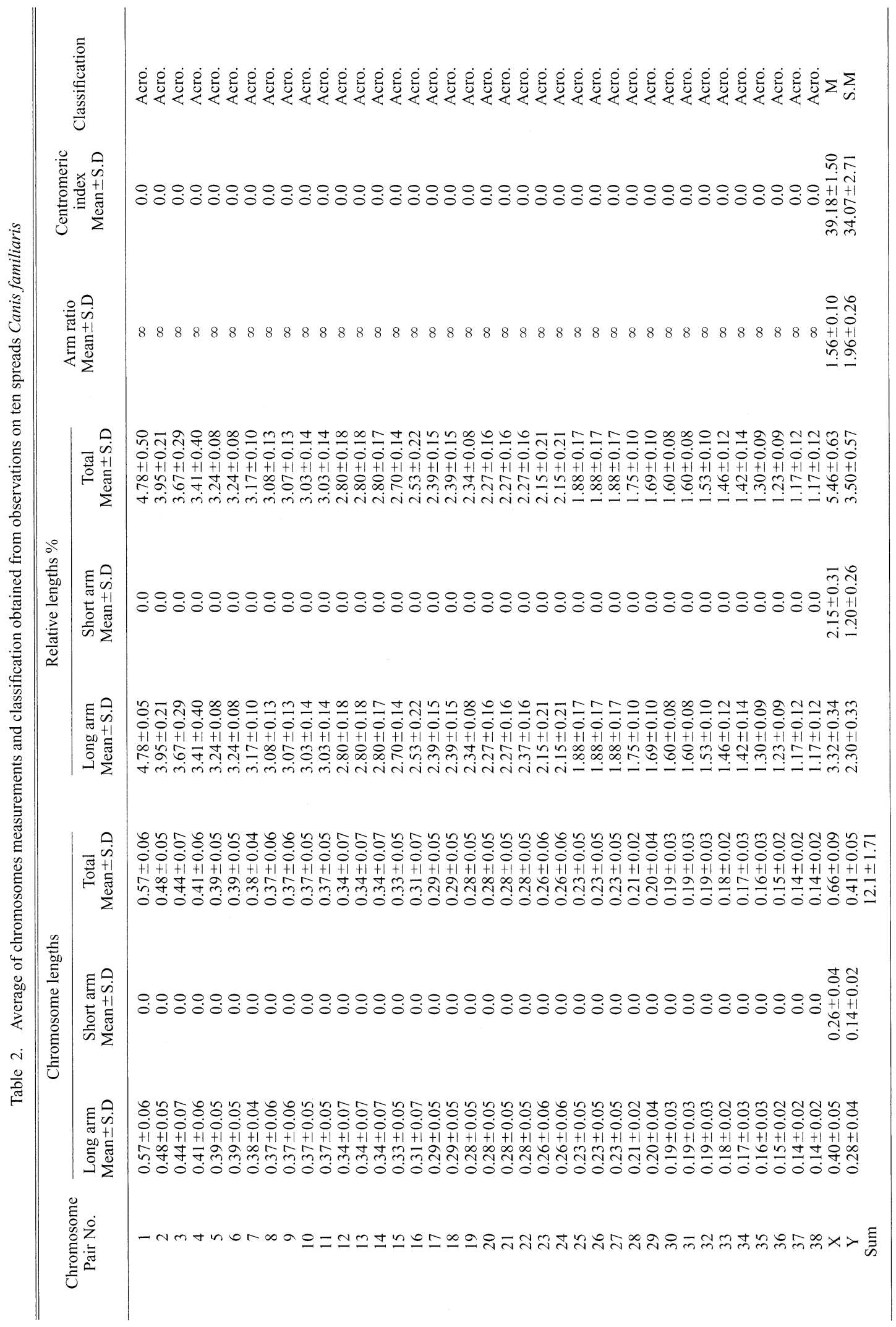




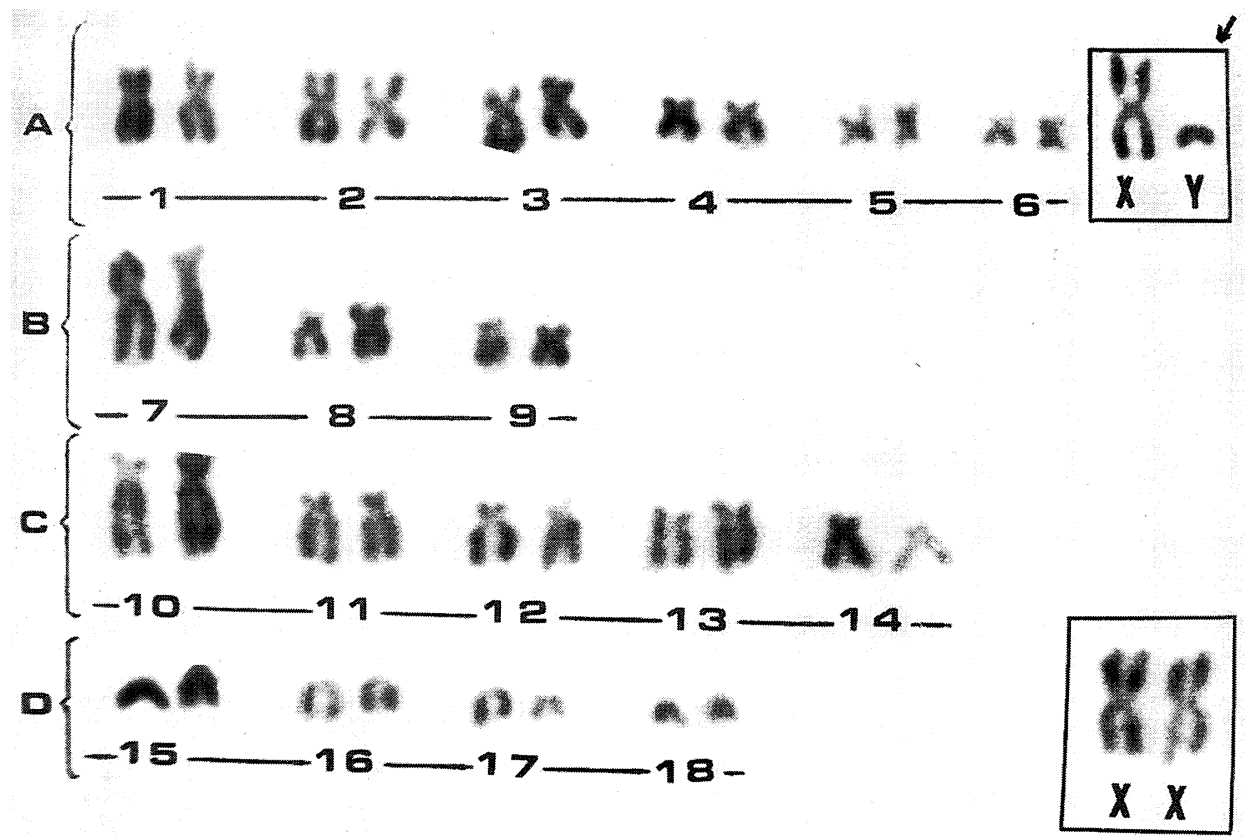

(a)
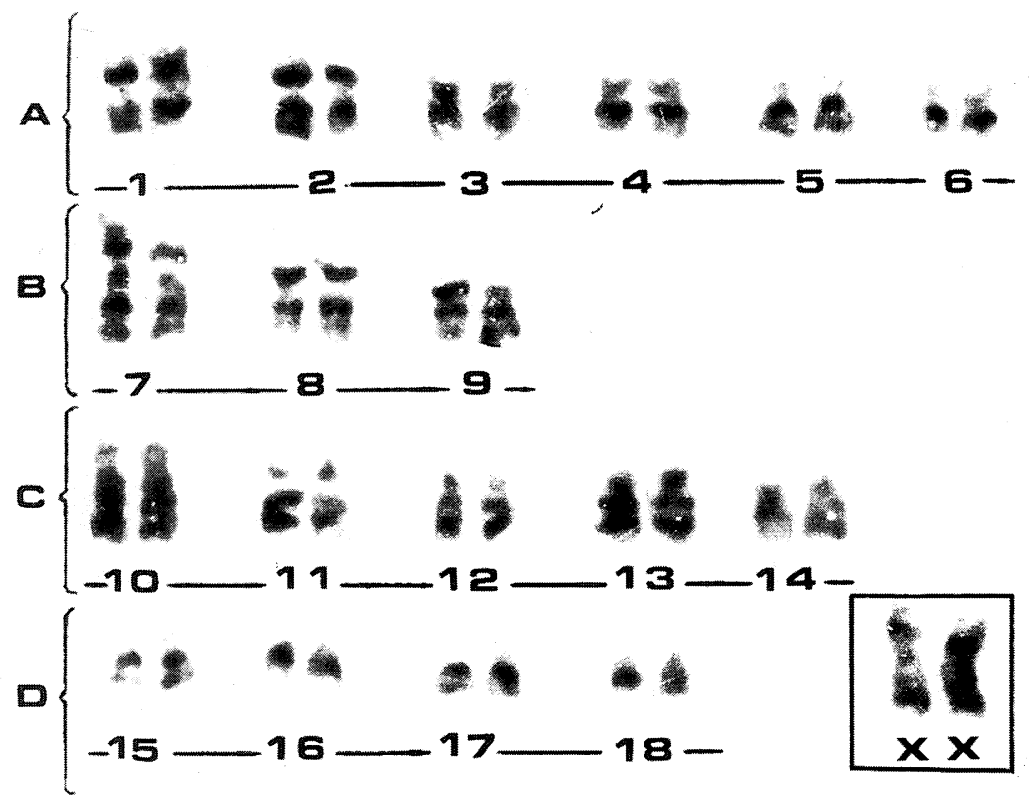

(b)

Fig. 5. Female mitotic karyotypes of Lycaon pictus, a) conventional Giemsa stain, b) G-banding, arrow indicates to sex chromosomes from a male. 


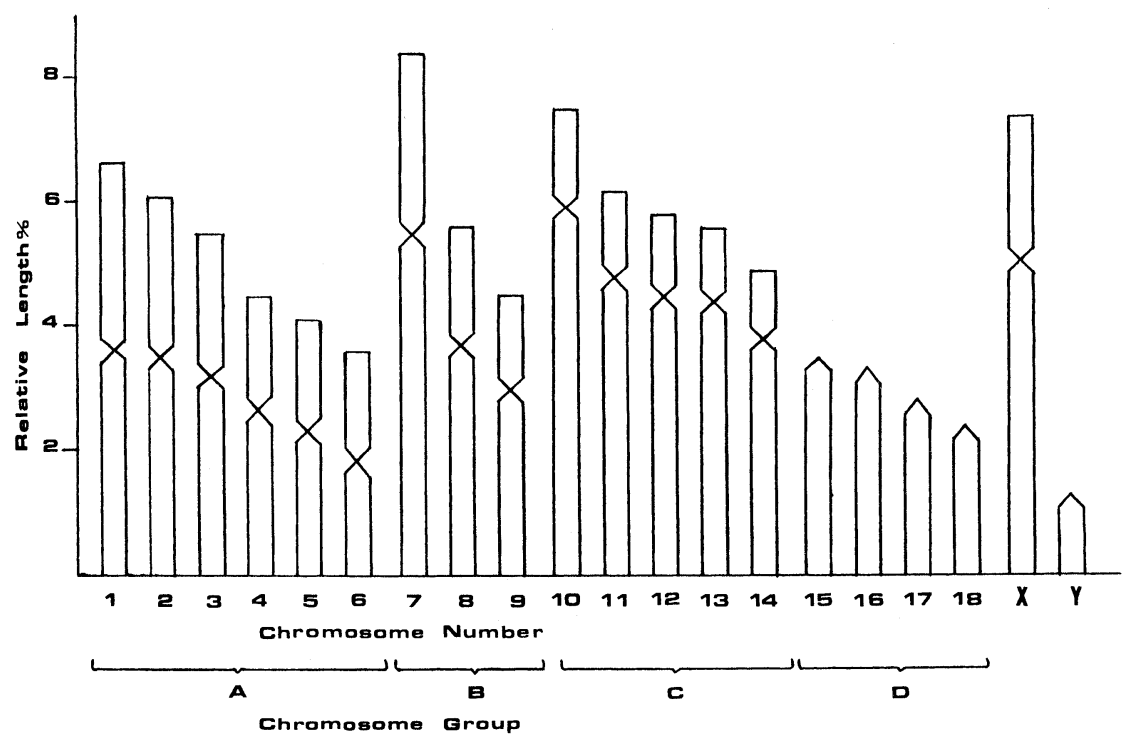

Fig. 6. Idiogram of the chromosomes of male Lycaon pictus which was constructed in respect to the relative length.

with Renzoni and Omodeo (1972) and Wayne et al. (1987). On the other hand, the canine diploid number was established as 78 (Gustavsson and Sundt 1964, Ford 1966, Chiarelli 1965, Mayr et al. 1986, Schimid and Guttenbach 1988). They also reported 76 acrocentric autosomes and two biarmed sex chromosomes. The karyotype of domestic dog (Fig. 3) confirm the previous reports. $C$. familiaris and C. lupus represent the highest autosomal complement of acrocentric chromosomes, while $V$. vulpes represents the highest autosomal complement of biarmed chromosomes of Canidae (Wurster-Hill and Centerwall 1982, Makinen 1985, Wayne et al. 1987).

The diploid number of L. pictus and its FN are located in-between the range of $2 \mathrm{n}$ and FN of Canidae as recorded by Ward et al. (1987). L. pictus which represents one of the wild canid species has a large number of biarmed autosomes (Figs. 5, 6) supporting the results of Chiarelli (1965) who found that the autosomes of wild dogs exhibite a great amount of large biarmed chromosomes suggesting fusion, while those of domestic dog is characterized by a totality of acrocentrics thus indicating fission. These results indicate the important role of Robertsonian changes in the karyotype evolution of Canids.

The karyotype and idiogram of Felis catus (Figs. 7, 8) with $2 \mathrm{n}=38$ and $\mathrm{FN}=72$ are in complete agreement with those reported for the most majority of individuals of Felidae which exhibit uniformity of the karyotype pattern (Wurster and Benirschke 1968, Ford et al. 1980, Wurster-Hill and Centerwall 1982), where 30 species have studies, 25 of them are reported to have a diploid chromosome number of 38 and 5 to have 36 , and the FN varies only from 70 to 76 .

\section{Acknowledgment}

The author wishes to thank Prof. Dr. Ahmed E. Yaseen for helpful discussion and critical remarks of the manuscript. 


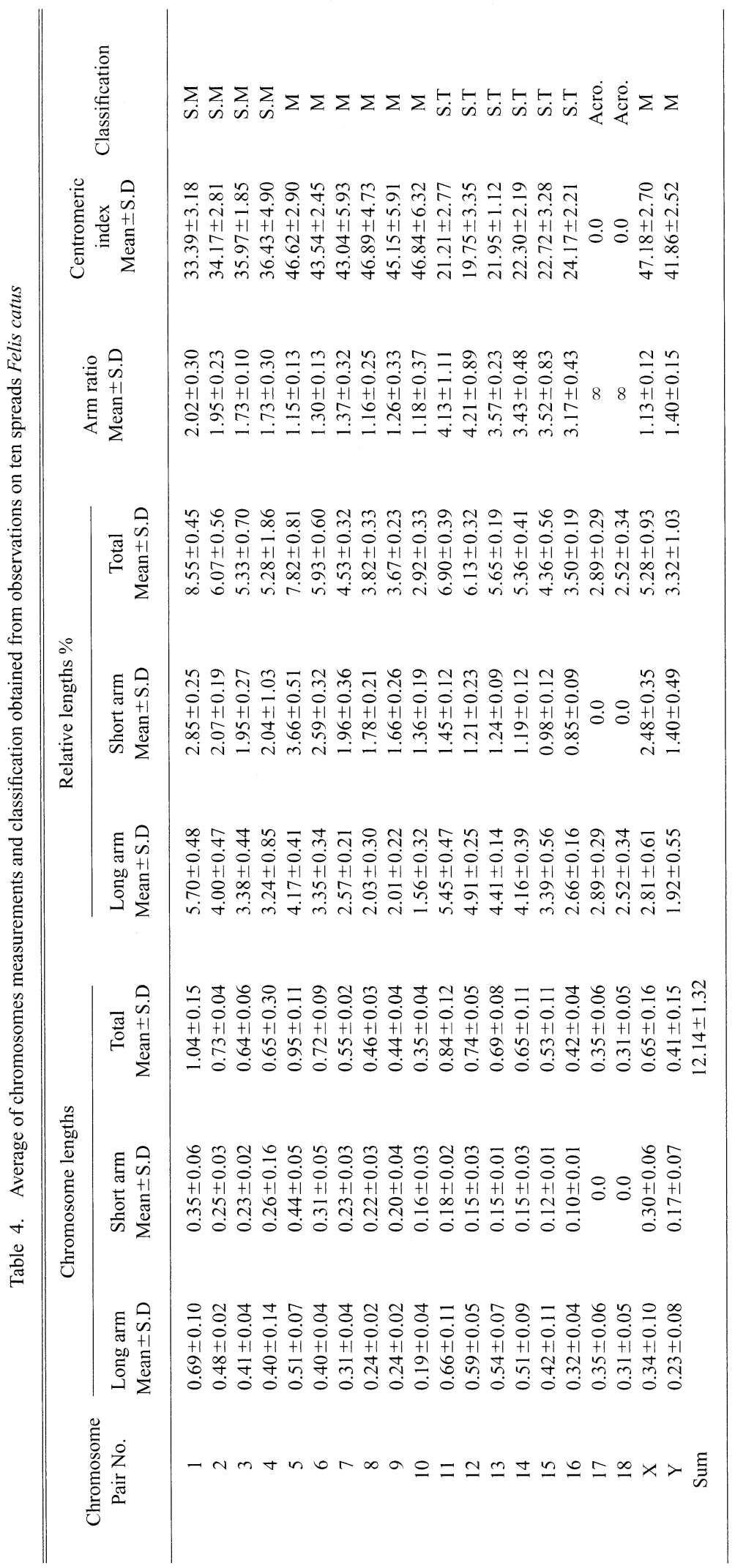




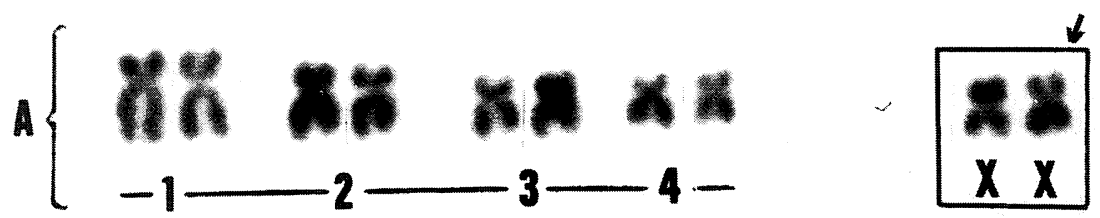

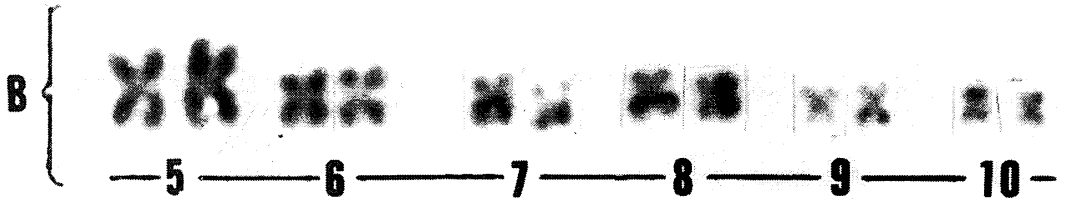
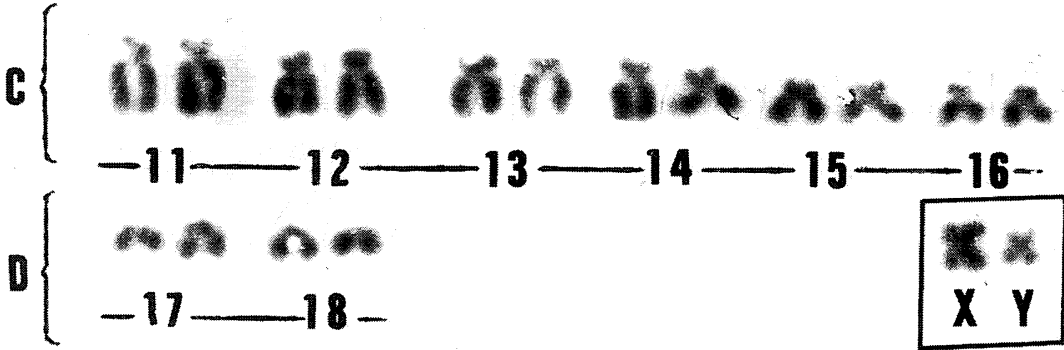

(a)
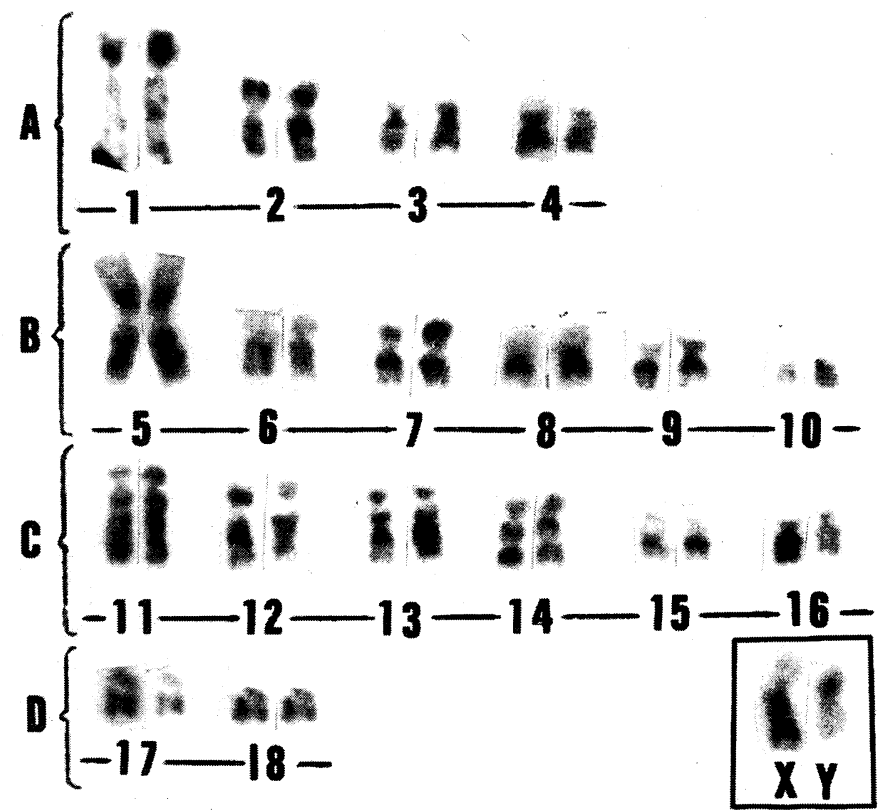

(b)

Fig. 7. Male mitotic karyotypes of Felis catus, a) conventional Giemsa stain, b) G-banding, arrow indicates to sex chromosomes from a female. 


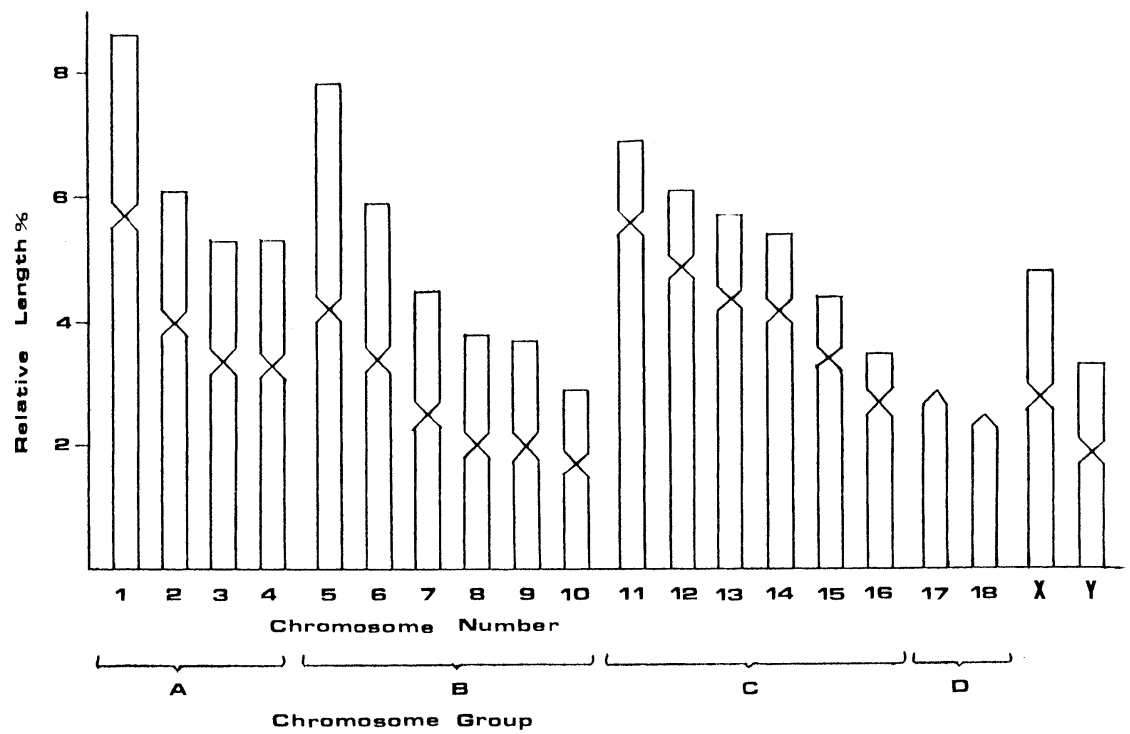

Fig. 8. Idiogram of the chromosomes of male Felis catus which was constructed in respect to the relative length.

\section{References}

Adegoke, J. A. and Ejere, V. C. 1991. Description of the chromosomes of three lizard species belonging to the genus Mabuya (Scincidae, reptilia). Caryologia 44: 333-342.

- and Nadesan, S. 1986. Karyotype and polyploidy in the bone marrow of the African fruit bat, Eidoloh belvum kerr. Nucleus 29: 107-112.

Andres, A. H. 1938. On the chromosomes complex in several canidae. Cytologia 9: 35-37.

Arnason, J. A. 1996. The complete mitochondrial DNA sequence of the greater Indian rhinoceros, rhinoceros unicornis and the phylogenetic relationships among carnivora, perssodactyla, and artiodactyla (plus cetacea). Mol. Biol. Evol. 13(9): 1167-1173.

Bichham, J. W. and Baker, R. J. 1976. Chromosome homology and evolution of Emydid Turtles. Chromosoma 54: $201-219$.

Bishop, D. W. 1942. Germ cells studies in the male fox (Vulpes fulva). Anat. Rec. 84: 99-115.

Chiarelli, B. 1965. Data on karyology of different races of Canis familiaris. Mammal. Chrom. Newsl. 21: 160.

Dutrillaux, B. and Couturier, J. 1983. The ancystral karyotype of carnivora comparison with that of platyrrhine monkeys. Cytogenet. Cell Genet. 35: 200-208.

Evans, H. J., Buckland, R. A. and Summer, A. T. 1973. Chromosome homology and heterochromatin in goat, sheep and ox studied by banding techniques. Chromosoma 42: 383-402.

Ford, L. 1966. The normal male and female dog mitotic karyotype. Mammal. Chrom. Newsl. 19: 3-4.

Ford, C. E., Pollock, D. L. and Gustavsson, I. 1980. Proceedings of the First International Conference for the Standardization of Banded Karyotypes of Domestic Animals, August 1976 (1980). Hereditas 92: 145-162.

Gustavsson, I. and Sundt, C. O. 1964. Chromosome complex of the family Canidae. Hereditas 54: 248-254.

Hassan, H. A., Yaseen, A. E. and Kawatshi, E. S. 1995. Cytogenetic survey of some common vertebrates. PhD thesis, Faculty of sicence, Assiut univ. Egypt.

Kalat, M., Mayr, B. and Schleger, W. 1990. Sequential counterstainenhanced banding: Heterochromatin characterization in the domestic cat (Felis catus). Caryologia 43: 183-189.

Laikre, L., Tegelstrom, H. and Gelter, H. P. 1992. DNA fingerprints of captive wolves (Canis lupus). Hereditas 117: 293-296.

Levan, A., Fredga, K. and Sandberg, A. A. 1964. Nomenclature for centromeric position on chromosomes. Hereditas 52: 201-220.

Makinen, A. 1985. The standard karyotype of the blue fox (Alopex lagopus L.). Hereditas 103: 33-38.

Mayr, B., Geber, G., Auer, H., Kalat, M. and Schleger, W. 1986. Heterochromatin composition and nucleolus organizer activity in four canid species. Can. J. Genet. Cytol. 28: 744-753.

Moorhead, P. S., Nowell, P. G., Mellman, W. J., Batipps, D. M. and Hungerford, D. A. 1960. Chromosome preparations of leukocytes cultures from human peripheral blood. Expt. Cell Res. 20: 613-616. 
Pathak, S., Hsu, T. C. and Helm, J. D. 1973. III Chromosome homology in the climbing rats, genus Tylomys (Rodentia: Cricetidae). Chromosoma 42: 215-218.

Qumsiyeh, M. B. 1994. Evolution of number and morphology of Mammalian chromosomes. J. Hered. 85: 455-465.

Renzoni, A. and Omodeo, P. 1972. Polymorphic chromosome system in the fox. Caryologia 25(2): 173-187.

Salama, S. A., Fahim, A. I. and Abuo El-Ghar, E. S. 1995. Chromosomal aberrations and sperms head abnormalities induced by Abamection and its degredates in male swiss Albine mice. Cytologia 60: 411-417.

Schmid, M. and Guttenbach, M. 1988. Evolutionary diversity of reverse (R) fluorescent chromosome bands in vertebrates. Chromosoma (Berl) 97: 101-114.

Seabright, M. A. 1971. A rapid banding technique for human chromosomes. Lancet ii: 971-972.

Suzuki, H., Hosoda, T., Sakurai, S., Tsuchiya, K., Munechika, I. and Korablev, V. P. 1994. Phylogenetic relationship between the Iriomote cat and the leopard cat, Felis bengalensis, based on the ribosomal DNA. Jpn. J. Genet. 69: 397-406.

Van Gebler, R. G. 1978. A review of canid classification. Am. Mus. Novitates 2646: 1-10.

Ward, O. G., Wurster-Hill, D. H., Ratty, F. J. and Song, Y. 1987. Comparative cytogenetics of Chinese and Japanese raccoon dogs, Nuctereutes procyomoides. Cytogenet. Cell Genet. 45: 177-186.

Wayne, R. K., Nash, R. K. and O'Brien, S. J. 1987. Chromosomal evolution of the Canidae. I. Species with high diploid numbers. Cytogenet. Cell Genet. 44: 123-133.

Wodsedalek, J. E. 1931. Spermatogenesis of the red fox (Vulpes vulpes). Anat. Rec. (Suppl.): 51-70.

Wurster, D. H. and Benirshke, K. 1968. Comparative cytogenetic studies in the order Carnivora. Chromosoma 24: $336-382$.

Wurster-Hill, D. H. and Centerwall, W. R. 1982. The interrelationships of chromosome banding patterns in canids, mustelids, hyena, and felids. Cytogenet. Cell Genet. 34: 178-192. 